\title{
JUVENTUDES E EDUCAÇÃO: \\ INVISIBILIDADES E EMERGÊNCIAS \\ NO PERCURSO HISTÓRICO BRASILEIRO
}

\author{
LUCIAN DA SILVA BARROS*
}

\begin{abstract}
RESUMO
O objetivo deste artigo é discutir a temática das juventudes e sua relação com a educação, adotando como recorte as concepções existentes a respeito desse período da vida no percurso histórico brasileiro. Como metodologia optou-se pela revisão da literatura, com o levantamento de pesquisas e discussões correlatas. Após a análise levantou-se a discussão de que, embora os jovens apareçam na cena social, eles são sempre vistos (ou quase não vistos) como sujeitos incompletos, imaturos irresponsáveis e, assim, desacreditados. São nomeados genericamente, o que torna ausente suas diferenças, divergências e multiplicidades. Considerou-se que um trabalho de percepção das diversidades (conhecimentos, tempo linguagens) que ultrapasse as noções universais descritas para os jovens é necessário para fazer emergir novas concepções que possibilitem a juventude brasileira ser sujeito de sua própria história. A educação e a escola, ao passo que reproduzem o modelo e a visão fragmentada desse período da vida, também são capazes de contribuir para a construção de novos significados do ser jovem, nos quais a diferenças e a alteridade sejam valorizados. Nesse campo a ação educativa assume importante papel, pois possibilita a ressignificação da concepção social a respeito da juventude, produzindo novos sentidos que deem lugar à transformação social. Palavras-chave: Cidadania. Educação. Juventudes. Diversidades. Sociologia das emergências.
\end{abstract}

* Psicólogo. Especialista em Educação e Orientação Profissional. Mestrando em Educação pela USCS. Docente do Senac SP. 


\begin{abstract}
The objective of this article is to discuss the theme of youth and its relationship with education, adopting as a clipping the existing conceptions regarding this period of life in the Brazilian historical path. As methodology it was decided to review the literature, with the research and related discussions. After the analysis, the discussion arose that, although young people appear on the social scene, they are always seen (or almost unseen) as incomplete, immature, irresponsible, and thus discredited subjects. They are named generically, which makes their differences, divergences and multiplicities absent. It was considered that a work of perception of the diversities (knowledge, time languages) that surpasses the universal notions described for the young people is necessary to give rise to new conceptions that allow the Brazilian youth to be subject of its own history. Education and school, while reproducing the fragmented model and vision of this period of life, are also capable of contributing to the construction of new meanings of the young being, in which differences and otherness are valued. In this field the educational action assumes an important role, since it allows the re-signification of the social conception regarding the youth, producing new senses that give place to the social transformation.
\end{abstract}

Keywords: Citizenship. Education. Youth. Diversities. Sociology of emergencies.

\title{
INTRODUÇÃO
}

Como os jovens são vistos pela sociedade? Esta visão se transformou ao longo da história? Como a educação e a escola lidam com as diferenças da juventude? É possível romper com um modelo que estigmatiza e universaliza os jovens de hoje?

A tematização da juventude na sociedade brasileira é uma questão que vem ganhando destaque nas últimas décadas. Considerar como os jovens se desenvolvem e são compreendidos pelo meio social é parte importante na construção de projetos (de educação, trabalho, assistência, entre outros) que os inclua de modo concreto, possibilitando o acesso a direitos e à parti- 
cipação social. Porém, apesar de ser constante nas discussões acadêmicas e nos meios de comunicação os jovens parecem invisíveis, pois nunca são ouvidos, entendidos e considerados como sujeitos que apresentam suas próprias questões, seus próprios desejos e necessidades.

Uma questão a ser abordada inicialmente diz respeito a terminologia adotada nesta discussão. A utilização do vocábulo "juventudes" (no plural) visa trazer à tona as desigualdades e diversidades existentes na juventude brasileira em diferentes períodos do desenvolvimento da sociedade/ contextos temporais bem como a partir do jogo simbólico cultural existente e das relações estabelecidas com seus meios de vida. Buscamos ampliar a concepção existente de uma juventude única e singular, para a compreensão da multiplicidade de experiências e vivências das "juventudes" no Brasil e no mundo.

Vale ainda relatar que as distinções feitas entre juventude e adolescência, em nossa visão, competem quase que exclusivamente aos campos teórico e de criação de políticas públicas. $\mathrm{Na}$ vida cotidiana e no senso comum, ambos os termos, figuram quase que como sinônimos. É possível dizer que, enquanto a adolescência com suas fases e características é tema de estudo recorrente da psicologia ${ }^{1}$, a juventude surge como temática para a sociologia, ciências políticas, economia, serviço social, entre outras ciências aplicadas. Em nossa visão, apesar de não serem sinônimos, juventude e adolescência são conceitos que se complementam, pois dizem respeito a um período da vida humana complexo, o qual é passível de múltiplas significações.

A Organização Pan-americana da Saúde/Organização Mundial da Saúde (OPAS/OMS, 2017) entende a adolescência como o período que se inicia aos 10 anos e se prolonga até os 19 anos, caracterizando-se como um processo biológico durante o qual se estrutura a personalidade. Entre os 10 e os 14 anos tem lugar a pré-adolescência (fase inicial) e entre os 15 e os 19

No campo da psicologia diversos teóricos descreveram aspectos relacionados ao desenvolvimento psicológico e social na adolescência, dentre estes destacam-se as teorizações de Sigmund Freud, Jean Piaget, Erik Erickson, James Marcia entre outros. 
anos temos então a adolescência propriamente dita (fase final). Nessa perspectiva, a adolescência então se definiria enquanto uma categoria psicológica e biológica. Já para a Organização das Nações Unidas (ONU, 2008) a adolescência compreende o recorte etário usado principalmente para fins estatísticos e políticos de 15 a 24 anos (youth) e se define pelo processo de preparação dos indivíduos para sua integração à sociedade, quando assumirá papéis de adultos no convívio social, tanto no plano familiar, quanto no profissional.

A OPAS destaca:

A adolescência é marcada, entre outras características, pela busca de autonomia sobre as decisões, emoções e ações, pelo desenvolvimento de habilidades e a vivência da sexualidade. É um período em que adolescentes exploram mais intensamente sua identidade sexual e de gênero (OPAS/ OMS, 2017, p. 7).

No Brasil, o Estatuto da Criança e do Adolescente/ECA (BRASIL, 1990) reconhece o adolescente como o sujeito com idade entre 12 e 18 anos, garantindo a este proteção especial e integral para que se desenvolva amparado por todos os direitos fundamentais e inerentes à pessoa humana (saúde, educação, segurança, trabalho, entre outros). O ECA, que serviu como diretriz para políticas implantadas durante a década de 90 e posteriormente os anos 2000, reafirma os tratados já afirmados na esfera mundial, que compreendem a infância e a adolescência como momentos do desenvolvimento que requerem maior atenção, cuidado e ações efetivas advindas da esfera pública, das famílias e de toda sociedade.

Ainda no Brasil, somente em 2013 - fruto de diversas lutas e reivindicações - foi promulgado o Estatuto da Juventude (BRASIL, 2013), que visa articular uma rede de apoio e atenção aos sujeitos com idade entre 15 e 29 anos. O Estatuto da Juventude visa fomentar e promover a participação social e política da juventude, assim como também assegurar os direitos 
à educação, à profissionalização, à diversidade e à igualdade ${ }^{2}$, à saúde, à cultura, à comunicação e à liberdade de expressão, ao desporto e ao lazer, à sustentabilidade e ao meio ambiente, à segurança pública e ao acesso à justiça (ESTATUTO DA JUVENTUDE, BRASIL, 2013, p. 26-33).

As políticas específicas de atenção aos jovens no Brasil surgem com maior força a partir dos anos 2000, culminando a promulgação do Estatuto da Juventude. Como destacam Pinheiro e Ribeiro (2016)

Em 2015, o país completou uma década de um potente ciclo de políticas públicas de juventude, iniciado com a Lei no 11.129, de 30 de junho de 2005, que criou a Secretaria Nacional de Juventude (SNJ), o Conselho Nacional de Juventude (Conjuve) e instituiu o "Programa Nacional de Inclusão de Jovens”, o Projovem, que seria o primeiro de um rol de programas e políticas públicas voltados diretamente para a inclusão, autonomia e emancipação da juventude brasileira. (PINHEIRO, RIBEIRO, 2016, p. 7)

Para a efetivação dos direitos previstos no Estatuto da Juventude, tornam-se necessárias a implementação de políticas e programas específicos para a juventude, nos quais haja a articulação de ações da União, dos estados e dos municípios, com vistas a construção de uma política nacional de atenção integral a juventude, a exemplo do realizado no Projovem ${ }^{3}$.

2 Com relação ao Do Direito à Diversidade e à Igualdade, o art. 17. Do Estatuto da Juventude, no traz que: $\mathrm{O}$ jovem tem direito à diversidade $\mathrm{e}$ à igualdade de direitos e de oportunidades e não será discriminado por motivo de: I - etnia, raça, cor da pele, cultura, origem, idade e sexo; II orientação sexual, idioma ou religião; III - opinião, deficiência e condição social ou econômica. (p. 29)

3 O Programa Nacional de Inclusão de Jovens - ProJovem, criado inicialmente como um programa emergencial e experimental tem como objetivo executar ações integradas que propiciassem aos jovens brasileiros a elevação do grau de escolaridade visando a conclusão do ensino fundamental, qualificação profissional voltada a estimular a inserção produtiva cidadã e o desenvolvimento de ações comunitárias com práticas de solidariedade, exercício da cidadania e intervenção na realidade local. 
De acordo com a ONU (2008), existem no mundo 1,2 bilhão de indivíduos entre 10 e 19 anos. Ao confrontar esses dados com os do Censo Demográfico de 2010 do Instituto Brasileiro de Geografia e Estatística (IBGE, 2010), segundo o qual a população adolescente representa atualmente 17,9\% do total dos brasileiros, um contingente superior a 34 milhões de pessoas, nos deparamos com um quadro preocupante. Mesmo diante dessa imensa multidão constata-se que suas necessidades e particularidades foram por muito tempo negligenciadas. As ações governamentais voltadas a esse público específico, as políticas públicas, não compreendem essa etapa da vida como um complexo processo de transformações psicossociais. (OPAS/ OMS, 2017).

Em face de tal panorama este artigo, como parte das discussões de uma dissertação de mestrado em desenvolvimento, visa discutir aspectos relacionados à juventude no Brasil e suas relações/tensões com a educação. O objetivo aqui é apresentar os resultados de uma revisão teórica realizada e fundamentada na condição social em que se inscreve a juventude hoje e na forma como é/foi representada historicamente. Objetiva-se ainda investigar a maneira com a educação e a escola auxiliam/ legitimam a construção de significados a respeito da juventude, com vista à produção de novos sentidos que tragam transformação social.

Os aportes teóricos utilizados para esta discussão partem dos trabalhos de Helena Abramo (1997), Miriam Abramovay et al (2004; 2010; 2015) e Juarez Dayrell (2003; 2007) a respeito da condição social da juventude brasileira nos diversos contextos temporais. Para embasar as proposições a respeito da invisibilidade das juventudes e da necessidade de emergência dos jovens na cena social como sujeitos de direitos e desejos próprios faremos uso dos conceitos de sociologia das ausências e sociologia das emergências, cunhados e defendidos por Boaventura de Souza Santos $(2002 ; 2007)$. Neste último ponto as aproximações feitas por Giuseppa Spenillo (2013) acerca das Epistemologias do Sul com as questões relacionadas às juventudes são úteis nas discus- 
sões, posto que abrangem o olhar historicamente construído a respeito da juventude, baseado em uma cultura adultocêntrica.

\section{MÉTODO}

Utilizamos como metodologia a abordagem qualitativa, tendo como instrumento a revisão de literatura com foco no levantamento de pesquisas correlatas. A partir das palavras-chave elencadas, buscamos, nas bases de dados, artigos relacionados ao tema para revisão e discussão.

\section{DISCUSSÃO}

A maneira como cada indivíduo compreende e vive o "ser jovem" (grifo nosso) recebe influências que variam de cultura para cultura, as quais dizem respeito ao estilo de vida vigente. Segundo Abramovay (2015), "A juventude é modelada na construção social de um tempo histórico" (p. 22). Para a autora o conceito de geração auxilia na explicação do surgimento de diferentes juventudes, conforme o tempo histórico vigente. Fazem parte da mesma geração, os jovens que experenciam, mesmo que de maneiras diferentes, os mesmos problemas históricos concretos. Em nossa compreensão, as juventudes são um espelho das sociedades em que se desenvolvem, refletindo seus problemas, angustias e avanços.

A revisão da literatura demonstrou as mudanças ocorridas ao longo da história no entendimento do sentido de juventude. As noções de infância e adolescência que passam a existir entre os séculos XIX e XX auxiliam na construção de um sentido de juventude até então não existem, uma vez que colocam os indivíduos mais novos de uma determinada sociedade em lugar de destaque. Porém, com a proximidade da vida adulta as tensões sociais aumentam - cabendo aos jovens reivindicarem seus espaços, na maioria das vezes negado pelo mundo do amadurecido.

Essa questão é abordada por Abramo (1997), para quem os discursos da ressocialização e da capacitação para o trabalho no Brasil (mão de obra muitas vezes não qualificada) fizeram parte das principais ações articuladas ao longo das últimas dé- 
cadas, principalmente por instituições de assistência social. Tais discursos ajudaram a forjar uma ideia de juventude passível de intervenção, a qual se não está amparada (atendida por alguma instituição) apresenta riscos à sociedade.

Nessa mesma linha de raciocínio, Abramovay (2015) defende que a sociedade brasileira, por meio de suas instituições (como a família e a escola, por exemplo), reflete dificuldades em conceber os jovens com identidades geracionais próprias, considerando-os adultos para algumas exigências e infantilizando-os para outras. Tal situação varia muito conforme a situação em que se encontram os diferentes jovens, estando profundamente relacionada ao seu gênero, raça e classe social. Jovens de classes sociais mais pobres estão expostos a situações e condições de vida muito diferentes dos jovens ricos e vice-versa. Assim como também jovens mulheres, negros e gays, entre outras segmentações que podem ser concomitantes ou mesmo se sobrepor, gerando vulnerabilidades a esses indivíduos. São situações que atravessam o jovem, possibilitando experiências muito diversas - ser uma jovem, mulher, negra, periférica, difere de ser um jovem, homem, gay, classe média baixa, não periférico.

Ao analisar, por meio da leitura dos artigos levantados, as visões dominantes a respeito do período juventude, é possível verificar a existência de explicações embasadas em concepções totalizadoras e reducionistas, que tomam alguns modelos de juventude como padrões. Estes padrões, que são repletos de estereótipos e estigmas, reforçam a ideia de um jovem universal. Nos tempos atuais vemos o surgimento da concepção de um jovem desconectado, apolítico, sem uma causa própria e sem nenhum sentido para sua vida - o que abordaremos mais à frente.

Ao aprofundar em suas investigações Dayrell (2003) constata que há socialmente certa tendência a se encarrar a juventude com negatividade. O jovem é aquele que "ainda não chegou a ser", sendo negada a importância das suas experiências vividas no momento presente, ou nas palavras do autor o seu "presente vivido". Com relação a isso, podemos dizer que o período da ju- 
ventude é socialmente menosprezado quando comparado com a vida adulta. Ao jovem sempre é dito "você é muito jovem tem muito a aprender" ou "ainda vai quebrar muito a cara por aí” (grifo nosso), o que deflagra que a juventude é concebida um momento de passagem onde o indivíduo aprende a ser adulto. No que se refere a decisões e posicionamentos, o jovem é sempre visto como instável e passível de mudanças constantes, não sendo considerado como alguém que tenha opiniões, desejos e vontades próprias, mas sempre como alguém em potencial, que virá a ser algo no futuro.

Para este autor, tal visão está presente, por exemplo, na escola, pois o jovem é sempre um "vir a ser" (grifo do autor) e nunca considerado com sujeito no tempo presente. Em nome do diploma e dos projetos de futuro o jovem deve negar suas vontades e desejos para atender aos anseios sociais para eles prescritos. A escola não compreende as vivências da juventude como uma possibilidade formativa.

Assim, o pesquisador reforça que

nos deparamos no cotidiano com uma série de imagens a respeito da juventude que interferem na nossa maneira de compreender os jovens. Uma das mais arraigadas é a juventude vista na sua condição de transitoriedade, na qual o jovem é um "vir a ser", tendo no futuro, na passagem para a vida adulta, o sentido das suas ações no presente. (DAYRELL, 2003, p. 40).

Juarez Dayrell (2003) chama ainda a atenção para a existência de uma visão romântica da juventude, existente principalmente a partir da década de 1960, a qual compreende esta etapa da vida como "um tempo de liberdade, de prazer, de expressão de comportamentos exóticos” (2003, p. 41). Tal percepção, já cristalizada, foi impulsionada pela indústria cultural e por um mercado de consumo dirigido exclusivamente aos jovens, o que até então não existia. Surge a partir daí uma moda, adornos, locais de lazer, músicas, revistas entre outros produtos que seriam pertinentes a uma cultura juvenil. Para o pesquisador, 
essa ideia romântica de juventude se aliou à noção de moratória - que concebe o período da juventude como um tempo para o ensaio e o erro, para novas experimentações, do qual seriam característicos a irresponsabilidade e o hedonismo. Diferentes imagens a respeito da juventude convivem ao longo dos tempos, não sendo possível traçar uma que seja unânime, porém todas minimizam as experiências juvenis, julgando-as como passageiras e pouco importantes.

A falta de engajamento dos jovens em atividades que, segundo os padrões sociais deveriam chamar sua atenção (relacionadas, por exemplo, à educação e ao trabalho formal), surge como assunto de diversas discussões na atualidade. O termo "geração nem-nem" vem sendo utilizado para designar a parcela dos jovens que não estudam e nem trabalham. São pessoas entre 18 e 25 anos que desistiram de procurar emprego pelo fato de não terem nenhuma qualificação, e tampouco querem voltar a estudar porque não se sentem atraídos pela escola.

A gênese dessa locução é explicado:

O termo "nem-nem" vem do termo em inglês NEET (Not in Education, Employment or Training) cunhada no Reino Unido durante a década de noventa para chamar a atenção ao expressivo número, em expansão na época, de jovens que, após a recessão da década de oitenta, não estavam engajados em acumular capital humano geral (através de educação formal) ou em participar do mercado de trabalho. (VASCONCELOS, RIBEIRO, GRIEBELER, CARRARO, 2017, p. 234).

Todavia, tal expressão vem sendo utilizada de modo pejorativo, como mais uma forma de estigmatizar e rotular uma significativa parcela da juventude contemporânea. Ao assim proceder não se está apresentando a complexidade da questão, uma vez que denota apenas aquilo que a sociedade considera que os jovens deveriam estar fazendo nesse momento da vida: estudar e trabalhar, estudar ou trabalhar. Dito por outras palavras, não colocam em discussão os aspectos que impedem a 
juventude de exercitar tais funções sociais, ou mesmo o que dificulta o seu acesso e participação nos espaços sociais e à vida produtiva.

Vasconcelos, Ribeiro, Griebeler e Carraro (2017), realizaram um estudo com o objetivo de verificar se a existência de programas de governo voltados a transmissão de renda como o Bolsa Família (PBF), por exemplo, poderia contribuir para o aumento da parcela de jovens que nem estudam e nem trabalham. Os autores levantaram evidências e concluíram que "ser beneficiário do PBF implica em um efeito positivo ao reduzir as chances de que os jovens adultos sejam "nem-nem" (p. 247), principalmente entre jovens que fazem parte da parcela de extrema pobreza do país. Para os autores, as condicionalidades do $\mathrm{PBF}$, elevam a importância dos jovens continuarem frequentando a escola e com isso elevarem as possibilidades de sua inserção no mercado de trabalho formal.

As proposições de Dayrell (2007), nos auxiliam na compreensão de como as juventudes brasileiras realizam a conciliação entre trabalho e estudo. Ressalta a maneira com que própria condição de trabalhador surge aos jovens como uma possibilidade de financiar sua condição juvenil, sem necessariamente abandonar os estudos. Percebemos que entre as juventudes mais pobres, o trabalho aparece também como uma possibilidade de financiar os estudos no ensino superior, geralmente em instituições privadas. Ao passo que a própria progressão educacional é almejada como uma forma de alcançar postos de trabalho mais valorizados e melhor remunerados.

No Brasil, a juventude não pode ser caracterizada pela moratória em relação ao trabalho, como é comum nos países europeus. Ao contrário, para grande parcela de jovens, a condição juvenil só é vivenciada porque trabalham, garantindo o mínimo de recursos para o lazer, o namoro ou o consumo. Mas isso não significa, necessariamente, o abandono da escola, apesar de influenciar no seu percurso escolar. As relações entre o trabalho e o estudo são variadas e complexas e não se esgotam na oposição entre os termos. Para os jovens, a escola e o trabalho são projetos que se superpõem ou pode- 
rão sofrer ênfases diversas, de acordo com o momento do ciclo de vida e as condições sociais que lhes permitam viver a condição juvenil. (DAYRELL, 2007, p. 1109)

Avançando na discussão, outras imagens distorcidas da juventude já estiverem presentes em relevantes momentos da história recente do Brasil. De acordo Abramo (1997), os jovens das décadas de 1950, 60 e 70 eram vistos apenas como rebeldes que queriam desafiar a ordem social, o governo, a tradição e os bons costumes. Porém, essa mesma juventude desacreditada em seu tempo, nos dias de hoje deslegitima as ações e movimentos da juventude atual, negando-lhes o direito de fazer valer suas vozes e opiniões. Os sujeitos jovens de outrora acreditam que os jovens de hoje ainda não são capazes de decidir por si próprios, além de agirem apenas por impulsos. Esse comportamento alimenta um ciclo que invalida tudo o que é pensando e feito pelos próprios jovens.

Num outro ângulo Spenillo (2013) propõe uma discussão acerca das juventudes usando como pressuposto as ideias de Santos $(2002$; 2007) e de diversos autores no campo das Epistemologias do $\mathrm{Sul}^{4}$, os quais entendem que o paradigma dominante atual é fundado no patriarcalismo, no capitalismo e no colonialismo. "Jovens seriam, então, sujeitos não sujeitos, tornados invisíveis pelas vontades do patriarca, do capital, do colonizador - ou tudo o que exerce esses papéis na vida de cada jovem" (SPENILLO, 2013, p. 21 e 22). É possível observar duas grandes manifestações da juventude atual: se por um lado ela se coloca nos cenários sociais e políticos sem autonomia e sem soberania, desenvolvendo hábitos de conformismo e adaptação às demandas do modelo hegemônico, por outro há movimentos de jovens que buscam protagonismo social, político e/ou cultural, por meio de diversos tipos de manifestações (movimentos secundários, hip hop, danças, entre outros) e por diferentes meios

As Epistemologias do Sul são um conjunto de procedimentos epistemológicos e de validação do conhecimento, com base nas práticas dos grupos sociais que historicamente são excluídos e sofrem as injustiças do capitalismo, do patriarcado e do colonialismo. 
(presenciais, virtuais, coletivo e individuais).

Para Spenillo (2013), apesar da existência de movimentos legítimos da juventude, com saberes e práticas próprios ${ }^{5}$, a produção das ausências ou "formas sociais de não-existência" (grifo da autora), destas mesmas juventudes desconsidera quaisquer conhecimentos produzidos e invalida os discursos e as reivindicações por mais espaços e direitos. "A produção social destas ausências resulta na subtração do mundo e na contracção do presente e, portanto, no desperdício da experiência" (SANTOS, 2010, p. 104). Quanto de experiências e saberes da juventude de décadas passadas a sociedade tem desperdiçado? E a escola nesse processo, tem sabido aproveitar os saberes da juventude na criação de comunidades de aprendizagem?

Ora encarada como a possibilidade de mudança e transformação social (o futuro da nação), ora a juventude é vista como um problema ou risco passível de intervenção e controle. Os moços aparecem na cena social, porém são sempre vistos (ou quase não vistos) como sujeitos incompletos, imaturos, irresponsáveis e desacreditáveis. São nomeados genericamente (jovens), o que torna ausente suas diferenças, divergências e multiplicidades. Mesmo em evidência, são invisibilizados por um discurso que nega suas individualidades e cooptados pelo jogo de consumo do capitalismo neoliberal. (SPENILLO, 2013)

A utilização do vocábulo "juventudes” (no plural) visa trazer à tona as desigualdades e diversidades existentes na juventude brasileira em diferentes períodos do desenvolvimento da sociedade/ contextos temporais, bem como a partir do jogo simbólico cultural existente e das relações estabelecidas com seus meios de vida.

Essa argumentação nos remete a Costa-Renders (2018), que defende que vivemos a monocultura do saber universal que produz sinais de morte em vida - parafraseando Paulo Freire -, sendo necessária uma urgente reconstrução, a qual exige

\footnotetext{
5 A exemplo desses movimentos temos o movimento de estudantes secundarista que ocupou diversas escolas de São Paulo em 2016, reivindicando o não fechamento das mesmas e o aumento da oferta de vagas.
} 
uma mudança cultural. A estudiosa entende que é preciso que as monoculturas deem lugar às ecologias, na sociedade e em especial no ambiente escolar. Para a autora, há a necessidade de "conversão do olhar classificatório e seletivo para o olhar relacional e solidário" (p. 57). A escola deveria trocar as práticas que classificam e selecionam os alunos - e como isso os excluem e estigmatizam -, por práticas mais inclusivas, de valorização das diferenças e dos repertórios individuais, proporcionando assim itinerários de formação mais personalizados que atendam aos sonhos e projetos de cada um.

Esse seguimento nos permite entender que as relações estabelecidas "na" e "com" a escola são fundamentais ao se discutir questões ligadas à juventude de diferentes períodos da história. Assim, chegamos ao entendimento de Miriam Abramovay (2015) de que a educação é um fenômeno social e universal, bem como uma atividade humana necessária à existência e ao funcionamento de todas as sociedades. A escola é um espaço de diversidades, no qual as diferenças existentes entre jovens e demais atores não podem se transformar em desigualdades. O discurso da educação também colabora para a construção de um jovem universal, uma vez que o ensino e a metodologia utilizados tornam-se rígidos, sem contemplar as trajetórias e características socioculturais dos sujeitos - principalmente da juventude historicamente. (ABRAMOVAY, 2015)

Para esta autora

$\mathrm{Na}$ escola, o jovem é despido da condição social de ser jovem e se transforma em "aluno", ou seja, é visto por uma perspectiva exterior a ele, em uma imposição normativa do sistema de ensino, perdendo-se de vista a diversidade, as buscas e os parâmetros de comportamento que fazem parte das modelagens de juventudes. A escola desconsidera, portanto, a cultura juvenil, a qual se caracteriza por ser dinâmica, diversa, flexível e móvel. (ABRAMOVAY, 2015, p. 31)

Frente à rigidez do sistema educacional formal, a desconexão entre o que se aprende na escola e o mundo real, a 
sensação de despreparo para o mundo do trabalho ou mesmo o ingresso no ensino superior frente as demandas do capitalismo e do vestibular, a pouca identificação com o espaço e ambiente escolar ${ }^{6}$ e ainda com os agentes desse contexto, encontramos um paradigma da educação atual que reforça a desvalorização e o não reconhecimento dos saberes e fazeres desses jovens que habitam e constroem o espaço da educação. Torna-se então necessário compreender que diferentes jovens, apresentam diferentes trajetórias de escolarização, sendo assim uma escola pensada para as juventudes precisa contemplar estes diferentes aspectos.

Esse modelo conflituoso é novamente abordado pela autora:

A educação e o trabalho aparecem como sendo as maiores reivindicações feitas pelos jovens e organizações juvenis [...]. Entretanto, o atendimento e a permanência dos jovens no ensino médio podem ser vistos como um dos desafios da atualidade ao se pensar em políticas públicas para juventudes no Brasil, frente ao crescimento da demanda. Destaca-se, nas formulações atuais sobre políticas de educação no Brasil, o interesse em problematizar diferenças e semelhanças entre as juventudes com base nas modalidades de ensino, além de outras categorias de análise, para entender se há motivações diferentes entre os que possuem diferentes trajetórias relacionadas à escolaridade. (ABRAMOVAY, 2015, p. 34)

É também investigado por Costa-Renders (2018). A pesquisadora acredita que as considerações de Boaventura de Sousa

6 A distinção entre espaço e ambiente escolar, refere-se ao fato de que a própria estrutura física e arquitetônica da escola (espaço) não é atrativa aos jovens, assim como a organização das aulas, a disciplina e as metodologias utilizadas (ambiente) revelam-se ultrapassadas. Se pegarmos como exemplos as escolas públicas de ensino médio, com algumas exceções, isso se agrava ainda mais, uma vez que não dispõem ao menos de laboratórios, recursos mínimos, banda larga de internet e outros aspectos pertinentes a escola do século XXI. 
Santos acerca da sociologia das ausências "pode iluminar essa discussão, pois nos remete ao enfrentamento dos modos de produção de ausência, substituindo monoculturas por ecologias" (2018, p. 57). Assim, constata-se que a escola deve criar espaço para a emergência dos saberes diferentemente sábios, das múltiplas temporalidades e dos reconhecimentos mútuos. Acreditamos ser necessário promover o enfrentamento do engessamento da escola e da educação, tendo como perspectiva a construção de novas ecologias neste espaço, no qual é necessário o reconhecimento do valor pedagógico das diferenças. Retomamos os estudos desta autora para fazer eco à sua afirmação: "Se a escola é uma comunidade de aprendizes, professores e professoras, como parte dessa comunidade, também são aprendizes". (COSTA-RENDERS, 2018, p. 58). Assim, os saberes trazidos pelos jovens à escola, contribuem para a formação e aprendizado de todos, cabendo aos profissionais da educação reconhecer e valorizar tais saberes.

\section{CONSIDERAÇÕES FINAIS}

As juventudes, historicamente nos referindo, vivem e experenciam esse momento da vida de modos muito particulares e por isso devemos estar abertos à ressignificação de conceitos. Essa percepção é também destacada por Abramovay (2015), segundo a qual "O reconhecimento de diversidades, diferenças e desigualdades tem enriquecido o debate sobre políticas de juventude" (ABRAMOVAY, 2015, p. 22). A promulgação do Estatuto da Juventude, em 2013, como uma lei que visa garantir o direito e a assistência aos jovens, representa importante avanço para se (re)pensar e abordar a questão da juventude - seja nas agendas de governo ou mesmo nas iniciativas da sociedade civil. Torna-se importante combinar, no campo da educação, trabalho, cultura e lazer, políticas universais, assim como também políticas mais focalizadas, considerando que existem distintos tipos de sujeitos jovens.

É necessário - e urgente - perceber e considerar as diferenças e diversidades (conhecimentos, tempos, linguagens) que ultrapassam as noções universais descritas sobre os jovens, 
permitir que emerjam novas concepções que possibilitem à juventude brasileira ser sujeito de sua própria história. A tradução intercultural proposta por Santos busca maior aproximação entre os saberes de modo recíproco; assim a questão da juventude no Brasil deve passar por esse processo de tradução a fim de que se busque novos caminhos para compreender a realidade dos jovens, seus modos de ser e de se expressar.

A educação e a escola, ao passo que reproduzem o modelo e a visão fragmentada sobre a juventude, também são capazes de contribuir para a construção de novos significados do ser jovem, nos quais a diferenças e a alteridade sejam valorizados. Nesse campo a ação educativa assume importante papel, pois possibilita a ressignificação da concepção social a respeito da juventude, produzindo sentidos que possibilitam a transformação social.

Ao disponibilizarmos aos jovens as ferramentas de que precisam para melhorar suas próprias condições de vida - por meio de ações educativas efetivas que produzam aprendizagens significativas e contextualizas, bem como o acesso ao mundo do trabalho com direitos resguardados, por exemplo, além de envolvê-los em esforços para melhorar suas comunidades -, estamos investindo na força de suas sociedades, para que sejam atores de transformação social.

Acreditamos que talvez somente dessa forma possamos alcançar os princípios elencados no Estatuto da Juventude, no qual a emancipação dos jovens ganha destaque, na medida em que tal iniciativa tem olhos voltados à trajetória de inclusão, liberdade e participação do jovem na vida em sociedade.

Vale a pena retomar esses princípios, como um guia para concepções/formulações inéditas a respeito da juventude em nosso país, visando ações efetivas que enxerguem os jovens como seres integrais.

I - promoção da autonomia e emancipação dos jovens; II - valorização e promoção da participação social e política, de forma direta e por meio de suas representações; III - promoção da criatividade e da participação no desenvolvimento do País; 
IV - reconhecimento do jovem como sujeito de direitos universais, geracionais e singulares;

$\mathrm{V}$ - promoção do bem-estar, da experimentação e do desenvolvimento integral do jovem;

VI - respeito à identidade e à diversidade individual e coletiva da juventude;

VII - promoção da vida segura, da cultura da paz, da solidariedade e da não discriminação;

VIII - valorização do diálogo e convívio do jovem com as demais gerações. (ESTATUTO DA JUVENTUDE, BRASIL, 2013, p. 26)

\section{REFERÊNCIAS}

ABRAMO, H. W. (1997). Considerações sobre a tematização social da juventude no Brasil. In: Revista Brasileira de Educação, São Paulo, n.5-6, p.2536. Disponível em: <http://anped.tempsite.ws/novo_portal/rbe/rbedigital/ RBDE05_6/RBDE05_6_05_HELENA_WENDEL_ABRAMO.pdf >. Acesso em: 09 fev. 2019.

ABRAMOVAY, M. et al. (2004). Juventudes e Sexualidade. Brasília: UNESCO, 2004

ABRAMOVAY, M. (2010). Gangues, gênero e juventudes: donas de rocha e sujeitos cabulosos. Brasília: Kaco Ed.; PPCAM; CUFA/DF; SDH/PR,.

. (2015). Juventudes na escola, sentidos e buscas: Por que frequen-

tam? Brasília-DF: Flacso - Brasil, OEI, MEC. Disponível em: < http://flacso. org.br/files/2015/11/LIVROWEB_Juventudes-na-escola-sentidos-e-buscas. pdf>. Acesso em: 09 fev. 2019.

BRASIL. (1990). Estatuto da Criança e do Adolescente: Lei $\mathbf{n}^{\mathbf{0}}$ 8.069, de 13 de julho de 1990. Brasília: Imprensa Oficial. Disponível em: < http://www. planalto.gov.br/ccivil_03/LEIS/L8069.htm>. Acesso em: 09 fev. 2019.

. (2013). Estatuto da Juventude: Lei no 12.852, de 5 de agosto de 2013.

Brasília: Imprensa Oficial. Disponível em: < https://www2.senado.leg.br/ bdsf/bitstream/handle/id/509232/001032616.pdf>. Acesso em: 09 fev. 2019. COSTA-RENDERS, E. C. (2018). A escola inclusiva na perspectiva das pessoas com deficiência. In: Cadernos de Pesquisa, São Luís, v. 25, n.3, Julho-Setembro. Disponível em: < http://www.periodicoseletronicos.ufma.br/ index.php/cadernosdepesquisa/article/view/9950>. Acesso em: 09 fev. 2019. DAYRELL, J. (2003). O jovem como sujeito social. In: Revista Brasileira de Educação, Rio de Janeiro, n.24, pág. 40-52, set/out/nov/dez. Disponível em: < http://www.scielo.br/pdf/rbedu/n24/n24a04.pdf>. Acesso em: 09 fev. 2019. . (2007) A escola "faz" as juventudes? reflexões em torno da socialização 
juvenil. In: Educação e Sociedade, Campinas, vol. 28, nº 100 - Especial, pág. 1105-1128, Outubro. Disponível em: < http://www.scielo.br/pdf/es/v28n100/ a2228100>. Acesso em: 09 fev. 2019.

INSTITUTO BRASILEIRO DE GEOGRAFIA E ESTATÍSTICA (IBGE), Censo Demográfico 2010. Rio de Janeiro: IBGE. Disponível em: https:// biblioteca.ibge.gov.br/visualizacao/periodicos/93/cd_2010_caracteristicas_populacao_domicilios.pdf. Acesso em: 09 fev. 2019.

ORGANIZAÇÃO DAS NAÇÕES UNIDAS (ONU). Departamento de Assuntos Sociais e Econômicos, Divisão de População. World Population Prospects: The 2008 revision. Disponível em: www.esa.un.org/unpd/ wpp2008/ index.htm. Acesso em: 09 fev. 2019.; e banco de dados globais do UNICEF. Acesso em: 09 fev. 2019.

ORGANIZAÇÃO PAN-AMERICANA DA SAÚDE/ORGANIZAÇÃO MUNDIAL DE SAÚDE (OPAS/OMS). Saúde e sexualidade de adolescentes. Construindo equidade no SUS. Brasília, DF: OPAS/OMS, MS, 71 p. Disponível em: <http://iris.paho.org/xmlui/handle/123456789/34279>. Acesso em: 09 fev. 2019.

PINHEIRO, D. RIBEIRO, E. (2016). Introdução. In: Agenda Juventude Brasil: leituras sobre uma década de mudanças, São Paulo: Instituto Pólis, pág. 185. Disponível em: <http://polis.org.br/publicacoes/10759-2/>. Acesso em: 09 fev. 2019.

SANTOS, B. S. (2002). Para uma sociologia das ausências e uma sociologia das emergências. In: Revista crítica de Ciências Sociais, Coimbra, nº 63, pág. $237-$ 280, Outubro. Disponível em: <http://www.boaventuradesousasantos.pt/media/pdfs/Sociologia_das_ausencias_RCCS63.PDF>. Acesso em: 09 fev. 2019. SANTOS, B.S. (2007). Renovar a teoria crítica e reinventar a emancipação social. São Paulo: Boitempo, 128p.

SPENILLO, G. M. D. . Juventudes, tecnologia, informação e conhecimento: discutindo caminhos epistemológicos. In: Revista cadernos de Ciências Sociais da UFRPE - Dossiê Juventudes, Recife, vol. 2 n 3, pág. 9-27, Julho-Dezembro. Disponível em: < http://www.journals.ufrpe.br/index.php/ cadernosdecienciassociais/article/view/346>. Acesso em: 09 fev. 2019.

VASCONCELOS, A. M. RIBEIRO, F. G. GRIEBELER, M. C. CARRARO, A. (2017). Programa Bolsa Família e Geração "Nem-Nem”: Evidências para o Brasil. In: Revista Brasileira de Economia, Rio de Janeiro, vol. 71, n ${ }^{\circ} 2$, pág. 233-257. Disponível em: < http://www.scielo.br/scielo.php?script=sci_ar ttext\&pid=S0034-71402017000200233 >. Acesso em: 09 fev. 2019. 


\section{SOBRE O AUTOR}

Lucian da Silva Barros - Psicólogo graduado pela Universidade Católica de Santos; Pós-graduado em Ética, valores e cidadania na escola pela Universidade de São Paulo e em Orientação Profissional e de Carreira pelo Instituto Sedes Sapientiae/SP; Mestrando em Educação pela Universidade Municipal de São Caetano do Sul; Professor e orientador de TCC do curso de Psicopedagogia EaD da Universidade Metodista de São Paulo; Docente do SENAC/SP, atuando com jovens aprendizes. E-mail: lucian.barros@hotmail.com 